\title{
Dynamics and mechanism of ultraviolet photolysis of atrazine on soil surface
}

\author{
Ajun Gong, Changming Ye, * Xingjun Wang, Zhifang Lei and Jianmiao Liu \\ Research Centre for Eco-Environmental Sciences, Chinese Academy of Sciences, PO Box 2871, Beijing 100 085, People's Republic of \\ China
}

\begin{abstract}
The photolysis of atrazine in the soil surface under UV light and the factors affecting this has been studied. A rate constant of 0.09-0.17 $\mathrm{min}^{-1}$, photolytic depth of 0.1-0.3 mm and half-life of 4-8 $\mathrm{min}$ were determined. The results show that soil granularity, pH, humidity, organic content, humic acid and surface-active agents could affect the photolysis of atrazine in soil. GC-MS showed three photolytic products: 1-sec-butyl-4,4-diethyl-1-tetrazene, $N^{2}, N^{4}$-diethyl-6-methyl-1,3,5-triazine-2,4diamine and 6-chloro- $N^{2}$-propyl-1,3,5-triazine-2,4-diamine. The mechanism of the photolytic process is discussed.
\end{abstract}

(C) 2001 Society of Chemical Industry

Keywords: atrazine; photolysis; soil; UV light

\section{INTRODUCTION}

Atrazine has been used extensively for the control of broad-leaf and grassy weeds in corn and other crops. Because of its persistence and wide and prolonged use, the possible contamination of surface and ground water supplies by this herbicide has become of environmental concern. ${ }^{1,2}$

Ultra-violet light causes the chemical modification of many pesticides under laboratory conditions. ${ }^{3}$ If such photodecomposition were to occur under field conditions, the results could be of major importance in predicting the environmental fate of such compounds in agricultural use. ${ }^{4,5}$

The photolysis of atrazine under UV light has been investigated by many workers. ${ }^{6,7}$ Hustert et $a l^{8}$ reported that atrazine is easily degraded by UV radiation in titanium dioxide suspensions or in the presence of hydrogen peroxide. Dilute aqueous solutions of atrazine in the $\mu \mathrm{g}$ litre ${ }^{-1}$ range could effectively be decontaminated by photocatalysis. Pelizetti et $a l^{9}$ investigated the photocatalytic degradation of atrazine in the presence of semiconductor metal oxide particles $\left(\mathrm{TiO}_{2}, \mathrm{ZnO}\right)$ suspended in aqueous solution under simulated sunlight irradiation. They observed that the weak photocatalytic activity of the soils suspended in aqueous solution $\left(2 \mathrm{~g}\right.$ litre $\left.^{-1}\right)$ was dramatically increased by the addition of $0.5 \mathrm{~g}$ of a semiconductor. The half-life was $10-40 \mathrm{~min}$, depending on the nature of the soil.

Many other studies have demonstrated that small additions of semiconductor oxides, such as $\mathrm{TiO}_{2}$ and $\mathrm{ZnO}$, to soil greatly increase the photodegradation rate of atrazine under simulated sunlight radiation. However, such semiconductors are often constituents of soil, so why did the soils themselves exhibit only a very weak catalytic activity towards atrazine? Most photolysis studies of atrazine have involved dilute aqueous suspensions of semiconductors and soil systems, which represent a considerable departure from the conditions which exist in most agricultural soils.

The present investigation deals with the fate of atrazine in the surface of agricultural soils under UV light. The influences of soil granularity, $\mathrm{pH}$, humidity, organic content, humic acid and surface-active agents were examined, and the major photolytic products and mechanism of decomposition explored.

\section{EXPERIMENTAL}

\subsection{Materials}

Atrazine was purchased from Ciba-Geigy (Basel, Switzerland). Humic acid (HA) and sodium dodecylbenzenesulfonate (DBS) were obtained from Beijing Chemical Reagent Corporation. A MILLI-Q pure water device was used. All organic solvents were of analytical reagent grade and were purified by distillation.

A soil with no history of atrazine application was obtained for this study from an orchard located at the north basin of Baiyangdian Lake, North China. The orchard itself had never been treated with atrazine and was $600 \mathrm{~m}$ from cornfields where this herbicide had been applied for 5 years. Soil samples were collected from the surface (top $10 \mathrm{~cm}$ ), freeze-dried and sieved

\footnotetext{
* Correspondence to: Changming Ye, Research Centre for Eco-Environmental Sciences, Chinese Academy of Sciences, PO Box 2871, Beijing 100 085, People's Republic of China

E-mail: yechm@mail.rcees.ac.cn

Contract/grant sponsor: National Natural Science Foundation, People's Republic of China; contract/grant number: 29777026 Contract/grant sponsor: Major Project Foundation, Chinese Academy of Sciences; contract/grant number: KZ951-B1-209-01

(Received 28 January 2000; revised version received 23 September 2000; accepted 4 October 2000)
} 
through a $120-\mu \mathrm{m}$ mesh. The composition of the soil was: clay $7-10 \%$, silt $25-35 \%$, sand $58-68 \%$ and organic matter $0.88-1.55 \%, \mathrm{pH} 7.8-8.0$.

\subsection{Photochemical measurements}

The irradiation device comprised a light-tight box containing a medium-pressure mercury lamp $(1000 \mathrm{~W})$ with a water-cooled quartz condenser and rotating sample shelf, so that the samples were $15 \mathrm{~cm}$ from the lamp. During photolysis reactions, the temperature was maintained at $28( \pm 2)^{\circ} \mathrm{C}$ by airconditioning. The UV intensity on the shelf, measured by a ZDZ-1 actinometer, was $2790 \mu \mathrm{W} \mathrm{cm}^{-2}$.

\subsection{Analysis of atrazine}

High-performance liquid chromotography (HPLC) measurements were carried out on a Shimadzu LC-6A instrument equipped with a Shimadzu SPD-1 detector. The stainless steel column $(25 \mathrm{~cm} \times 4.6 \mathrm{~mm}$ ID) was packed with DuPont ODS chemically-bonded phase $(10 \mu \mathrm{m})$, and was pre-tested by the manufacturer. A wavelength of $235 \mathrm{~nm}$ was used for all measurements. Samples were eluted with methanol+ water $(80+20$ by volume) at a flow-rate of $0.8 \mathrm{ml}$ $\min ^{-1}$. Mass spectra were obtained using an LK 9000 GC-MS (LKB Instruments Inc, Rockville, MD, USA) Samples were introduced by a direct probe into the ionization source, or indirectly by means of a gas chromatograph. The latter was accomplished using an SE-30 column (1\% w/w on 60/80 mesh Gas-Chrom Q) with a column temperature ranging from 80 to $320^{\circ} \mathrm{C}$.

\subsection{Photochemical procedures}

In order to study the effect of the various factors on photolysis, six types of experiment were carried out (see Table 1). Methanol solutions of atrazine (1 mg $\mathrm{ml}^{-1}$ ) were applied uniformly to soil samples. After the solvent had been allowed to evaporate, the soil samples were ground and sieved. In the appropriate tests, HA and DBS were added directly to the soil prior to grinding.

The atrazine-treated soil samples were sieved uniformly onto the surface of plates (diameter $8.7 \mathrm{~cm}$ ) to give an average soil thickness of $0.2-0.5 \mathrm{~mm}$ and then irradiated in the irradiation device. Samples were

Table 1. Variables examined for effect on atrazine photolysis

\begin{tabular}{ll}
\hline Test & \multicolumn{1}{c}{ Variables included in test } \\
\hline A & $\begin{array}{c}\text { Soil granularity, organic substances, } \mathrm{pH} \text { value: in dry } \\
\text { natural soils }\end{array}$ \\
B & $\begin{array}{c}\text { Soil granularity, organic substances, } \mathrm{pH} \text { value: in wet } \\
\text { natural soils }\end{array}$ \\
C & Sand, silt, clay, without organic substances \\
D & Humic acid \\
E & Surface-active agent \\
F & Humic acid and surface-active agent \\
\hline
\end{tabular}

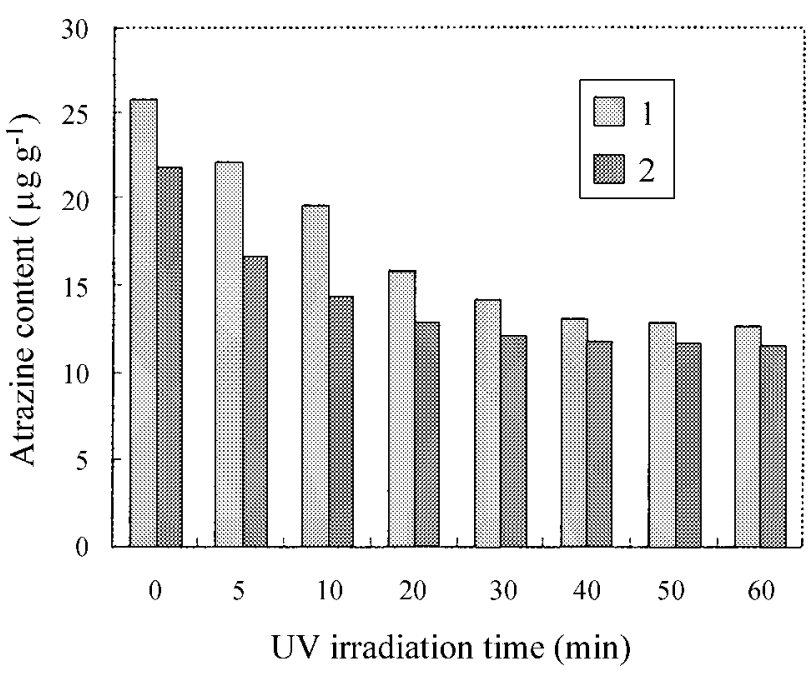

Figure 1. Photolytic curves with soils $\mathbf{1}$ and $\mathbf{2}$.

taken out at 5-min intervals, weighed, placed in beakers, extracted three times with methanol, concentrated, cleaned up and analysed for atrazine by HPLC. Figs 1 and 2 show the variation of atrazine content with time for soils 1, 2, 3 and 4. These are typical of the curves obtained in all the tests, allow the calculation of a range of parameters, as described in Section 3.1 and 3.2.

\section{RESULTS AND DISCUSSION}

\subsection{Photolytic depth for atrazine in soil}

Atrazine was photolysed only in a very thin surface layer because of the low transmission of light and slow movement of atrazine in soil. On the basis of atrazine residues, soil depth, sample weight and soil density, the photolytic depth, ie the maximum depth at which

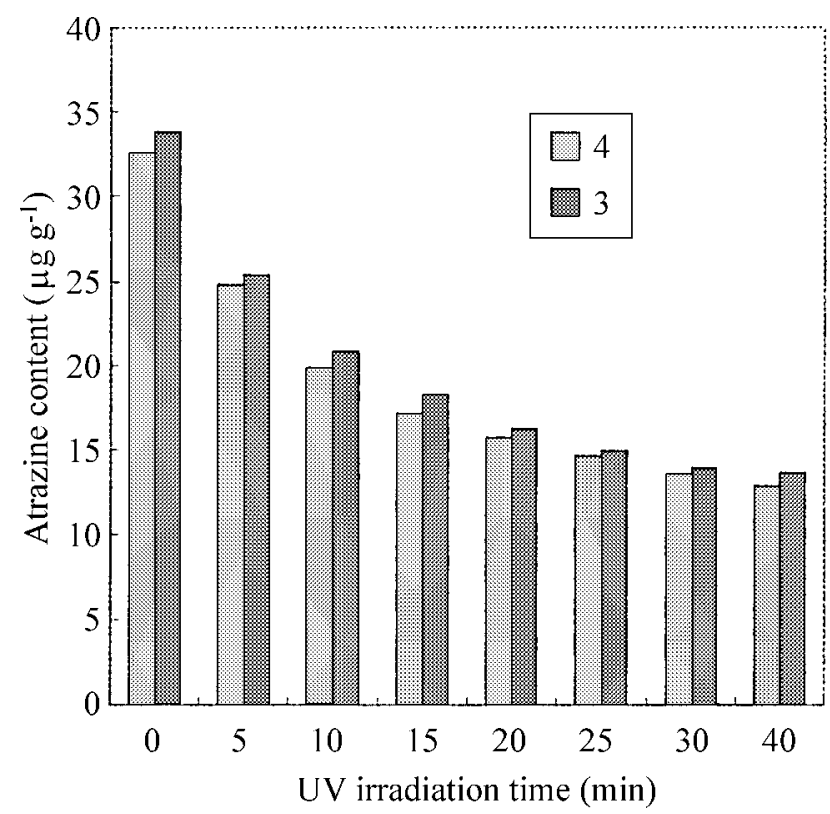

Figure 2. Photolytic curves with soils $\mathbf{3}$ and $\mathbf{4}$. 


\begin{tabular}{lllllllll}
\hline & \multicolumn{8}{c}{ Soil sample number } \\
\cline { 2 - 9 } Characteristic & $\mathbf{1}$ & $\mathbf{2}$ & $\mathbf{3}$ & $\mathbf{4}$ & $\mathbf{5}$ & $\mathbf{6}$ & $\mathbf{7}$ & $\mathbf{8}$ \\
\hline Sand (\%) & 46.1 & 60.7 & 56.4 & 56.5 & 46.1 & 46.1 & 46.1 & 46.1 \\
Silt (\%) & 47.9 & 37.5 & 41.00 & 41.2 & 47.8 & 47.8 & 47.8 & 47.8 \\
Clay (\%) & 6.06 & 1.80 & 2.61 & 2.34 & 6.06 & 6.06 & 6.06 & 6.06 \\
Organics (\%) & 1.454 & 1.442 & 1.615 & 0.873 & 1.454 & 1.454 & 1.454 & 1.454 \\
pH & 8.63 & 8.65 & 8.31 & 8.73 & 3.34 & 5.58 & 8.63 & 10.10 \\
Water (\%) & 0 & 0 & 0 & 0 & 50 & 50 & 50 & 50 \\
\hline
\end{tabular}

Table 2. Characteristics of four soils used in tests $\mathbf{A}$ and $\mathbf{B}$

photolysis occurred, could be calculated as follows:

$$
P=H \times(1-R)=W(1-R) / D \times A
$$

where $P=$ photolytic depth, $H=$ total thickness of soil layer, $R=$ percentage of atrazine remaining at equilibrium, $W=$ total soil mass, $D=$ soil density, and $A=$ soil area.

\subsection{Rate of photolysis of atrazine}

It is difficult to calculate the photocatalytical rate exactly because of the complexity of the soil, but provided that the photolysis of atrazine follows a firstorder reaction, the rate constant $k_{\mathrm{s}}$ can be calculated approximately from:

$$
\ln \left(C_{\mathrm{o}} / C_{t}\right)=k_{\mathrm{s}} t
$$

Because UV light penetrates the soil surface only to a depth of less than $0.3 \mathrm{~mm}$, atrazine in the lower layers is not photolysed, and this must be allowed for. The above expression thus has to be modified to:

$$
\begin{gathered}
\ln \left(C_{\mathrm{o}} / C_{t}^{\prime}\right)=k_{\mathrm{s}} t \\
C_{t}^{\prime} / C_{\mathrm{o}}=\left(C_{t} / C_{\mathrm{o}}-C_{\mathrm{e}} C_{\mathrm{o}}\right) /\left(1-C_{\mathrm{e}} / C_{\mathrm{o}}\right) \\
=\left(C_{t}-C_{\mathrm{e}}\right) /\left(C_{\mathrm{o}}-C_{\mathrm{e}}\right) \\
C_{t}^{\prime}=\left(C_{t} W-C_{\mathrm{e}} W\right) /(W \times P / H)
\end{gathered}
$$

where $C_{\mathrm{o}}=$ original concentration of atrazine, $C_{t}^{\prime}=$ concentration of atrazine in photolysed layer at time $t$, $C_{t}=$ measured overall concentration of atrazine at time $t, C_{\mathrm{e}}=$ measured overall concentration of atrazine at equilibrium, $W=$ total soil mass, $P=$ photolytic depth, $H=$ overall soil depth and $k_{\mathrm{s}}=$ rate constant.

\subsection{Test A: photolysis of atrazine in dry natural soils}

Four model soil samples were used to study the effects of soil granularity and organic matter on atrazine photolysis (Table 2). The four samples were spiked with atrazine, irradiated for different times, and then analysed by HPLC.

The organic content and $\mathrm{pH}$ of samples $\mathbf{1}$ and $\mathbf{2}$ were similar, but they differed in granularity. The photolytic depths, rate constants and half-lives are shown in Table 3. Both the photolysis rate and photolytic depth were somewhat greater for the finer soil, $\mathbf{1}$, than for the coarser soil, $\mathbf{2}$, indicating that the coarser the soil, the less the UV penetration.

The granularities and $\mathrm{pH}$ values of $\mathbf{3}$ and $\mathbf{4}$ were similar, but they differed in organic content. The photolysis rate in $\mathbf{3}$ was slightly greater than that in $\mathbf{4}$, (Table 3) but the photolytic depths were similar, indicating that organic substances increase the photolysis of atrazine, but do not affect the photolytic depth.

\subsection{Test B: photolysis of atrazine in wet natural soils}

The four soil samples used in this test, 5-8, had similar constituents and water contents, but their $\mathrm{pH}$ values ranged from 3.34 to 10.10 (Table 2). The characteristic parameters are given in Table 3 . The rate of photolysis of atrazine was slowest in neutral soil when other conditions were constant, and increased with increase of both acidity and basicity, showing that both $\mathrm{H}^{+}$and $\mathrm{OH}^{-}$ions are able to catalyse the photochemical reactions.

Soil 1 (test A) and soil 7 (test B) had similar constituents and $\mathrm{pH}$ values, but different moisture contents. The experimental results indicated that the rate constant, $k_{\mathrm{s}}$ for $7\left(0.144 \mathrm{~min}^{-1}\right)$ was greater than that for $1\left(0.0904 \mathrm{~min}^{-1}\right)$. The photolytic depth, $H$, was also greater for $7(0.26 \mathrm{~mm})$ than for $1(0.16 \mathrm{~mm})$.

Table 3. Photolytic data for the six tests

\begin{tabular}{llcccc}
\hline Test & $\begin{array}{c}\text { Sample } \\
\text { number }\end{array}$ & $\begin{array}{c}\text { Soil } \\
\text { depth } \\
\mathrm{H}(\mathrm{mm})\end{array}$ & $\begin{array}{c}\text { Photolytic } \\
\text { depth } \\
\mathrm{P}(\mathrm{mm})\end{array}$ & $\begin{array}{c}\text { Rate } \\
\text { constant } \\
\mathrm{k}_{\mathrm{s}}\left(\mathrm{min}^{-1}\right)\end{array}$ & $\begin{array}{c}\text { Half-life } \\
\mathrm{t}_{1 / 2}(\mathrm{~min})\end{array}$ \\
\hline $\mathbf{A}$ & $\mathbf{1}$ & 0.31 & 0.16 & 0.0904 & 7.7 \\
& $\mathbf{2}$ & 0.33 & 0.15 & 0.0873 & 7.9 \\
& $\mathbf{3}$ & 0.48 & 0.29 & 0.1291 & 5.4 \\
& $\mathbf{4}$ & 0.45 & 0.27 & 0.1049 & 7.1 \\
$\mathbf{B}$ & $\mathbf{5}$ & 0.46 & 0.28 & 0.2232 & 3.1 \\
& $\mathbf{6}$ & 0.47 & 0.27 & 0.1990 & 3.5 \\
& $\mathbf{7}$ & 0.45 & 0.26 & 0.1440 & 4.8 \\
& $\mathbf{8}$ & 0.46 & 0.27 & 0.1763 & 3.9 \\
$\mathbf{C}$ & Dry sand & 0.18 & 0.08 & 0.1128 & 6.1 \\
& Dry silt & 0.20 & 0.11 & 0.1184 & 5.9 \\
& Dry clay & 0.32 & 0.15 & 0.1340 & 5.2 \\
& Wet sand & 0.25 & 0.13 & 0.1179 & 5.9 \\
& Wet silt & 0.28 & 0.16 & 0.1260 & 5.5 \\
& Wet clay & 0.30 & 0.18 & 0.1400 & 5.0 \\
D & Humic acid & 0.28 & 0.16 & 0.1260 & 5.5 \\
& No humic & 0.29 & 0.20 & 0.1473 & 4.7 \\
& $\quad$ acid & & & & \\
E & DBS & 0.28 & 0.16 & 0.1260 & 5.5 \\
& No DBS & 0.30 & 0.18 & 0.1332 & 5.2 \\
F $\quad$ HA DBS & 0.28 & 0.16 & 0.1260 & 5.5 \\
& No HA/DBS & 0.29 & 0.22 & 0.1609 & 4.3 \\
\hline
\end{tabular}


This suggests that water assists the movement of atrazine from the inner layers to the surface of the soil. It may also assist the removal of the photolytic products, thus overall accelerating the photolysis of atrazine.

\subsection{Test C: photolysis of atrazine in soil without organic substances}

A soil sample, not containing atrazine, was placed in a beaker, moistened with a little water and mixed with hydrogen peroxide to remove organic substances. It was then washed into a $1000-\mathrm{ml}$ flask and separated by Stokes' method according to particle size: sand $(0.125-0.9 \mathrm{~mm})$, silt $(20 \mu \mathrm{m}-0.125 \mathrm{~mm})$ and clay

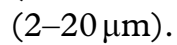

The parameters for these fractions under dry conditions are given in Table 3. The photolysis rate of atrazine and photolytic depth increased gradually from sand through silt to clay. This probably relates to the increase in surface area; the smaller the particle size, the greater the surface area per unit mass, and hence the greater the catalytic capability.

In the presence of $50 \%$ of water, the relationship with particle size was similar to that found under dry conditions (Table 3), but in each case the rates of photolysis were higher, again emphasising the importance of water in atrazine photolysis.

\subsection{Test D: influence of humic acid on atrazine photolysis}

Based on the levels used in other work, ${ }^{10}$ and taking into account possible interference with HPLC, silt samples free from organic substances were spiked with humic acid (20 mg per 1000-g sample) and 50\% of water. The parameters are given in Table 3. The photolytic rate constant and photolytic depth were increased in the presence of humic acid, and the rate constant decreased, supporting the view that it can catalyse the photolysis of atrazine and accelerate the process.

\subsection{Influence of dodecyl benzenesulfonate on atrazine photolysis}

Based on the levels of dodecyl benzenesulfonate (DBS) used in other work and possible interference in HPLC, organic-free silt samples were spiked with DBS (20 mg per 1000-g sample) and 50\% of water. The photolytic parameters are given in Table 3. In the presence of DBS the photolytic rate and photolytic depth increased slightly and the half-life decreased slightly. The influence of DBS on the photolysis of atrazine is less than that of humic acid, and is probably due to its ability to enhance the solution of atrazine and so increase its movement and that of its photolysis products.

\subsection{Comparative experiments}

In order to test the possible influence of biodegradation and hydrolysis, tests were carried out in comparison with the above, except that the samples were kept

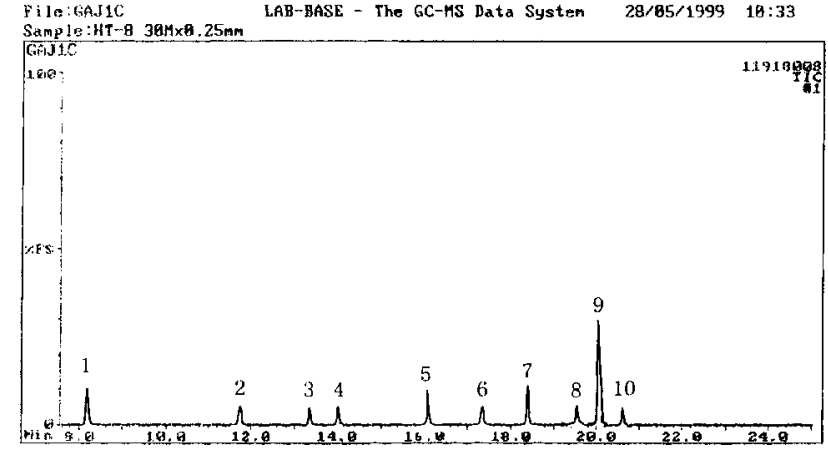

Figure 3. GC-MS chromatogram of photolytical products of atrazine.

in darkness at $28^{\circ} \mathrm{C}$ for $40 \mathrm{~min}$. The results indicated (data not shown) that the effects of these factors were so small that they could be neglected in comparison with photolysis.

\subsection{Analysis of photolysis products}

In order to minimise the effects of impurities and to increase the content of photolysis products, organic compounds were removed from the soil. The soil comprised sand $46 \%$, silt $48 \%$ and clay $6 \%$. Atrazine (50 mg per $1000 \mathrm{~g}$ of soil) was spiked onto soil samples, which were then sieved onto a tray as before, carefully wetted to a level of $50 \%$ and irradiated in the photolysis chamber. The degradation products were extracted with methanol + dichloromethane + acetone $(1+1+1$ by volume) and analysed by GC-MS.

The CG-MS chromatogram obtained is shown in Fig 3. Careful analysis confirmed the presence of three photolysis products: 1-sec-butyl-4,4-diethyl-1-tetrazene (peak 1), $N^{2}, N^{4}$-diethyl-6-methyl-1,3,5-triazine-2,4-diamine (peak 5) and 6-chloro- $N^{4}$-propyl1,3,5-triazine-2,4-diamine (peak 7). Their mass spectra are shown in Figs 4-6, and their structures in Fig 7.

\subsection{Stages in the photolytic process}

From the results of the above experiments, the photolysis of atrazine is seen as involving five steps: (1) movement of atrazine to the surface of the soil granule; (2) adsorption of atrazine on the surface of the soil granule; (3) under UV irradiation, the bonds in the atrazine molecule are distorted, forming active inter-

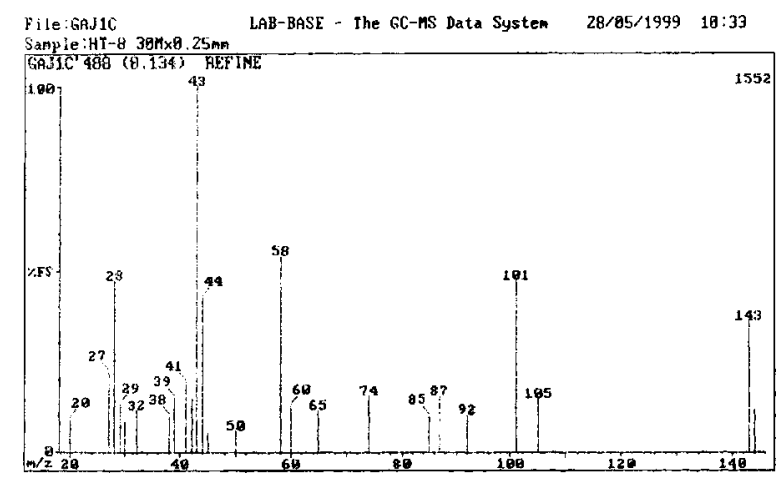

Figure 4. Mass spectrum of 1-sec-butyl-4,4-diethyl-1-tetrazene. 


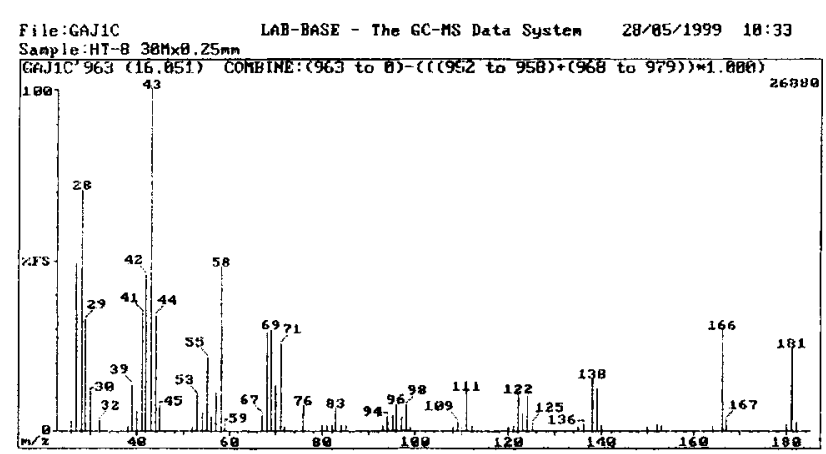

Figure 5. Mass spectrum of $N^{2}, N^{4}$-diethyl-6-methyl-1,3,5 triazine-2,4diamine. mediate products; (4) the active intermediates undergo rearrangement, or are broken up, to form new compounds - the photo-degraded products; (5) these products leave the surface of the soil granule.

Water and surface-active agents facilitate the desorption of atrazine from organic substances in the soil and speed the movement of atrazine and its decomposition products. They thus enhance the<smiles>CCNc1nc(Cl)nc(NCC)n1</smiles>

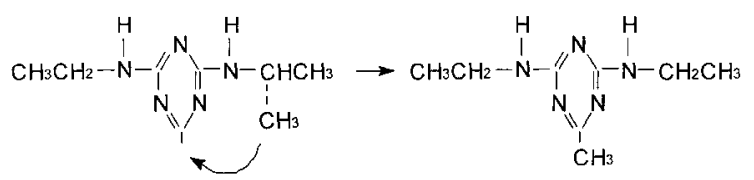

File:GAJ1C LAB-BASE - The GC-MS Data System 28/65/1999 10:33

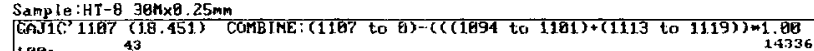

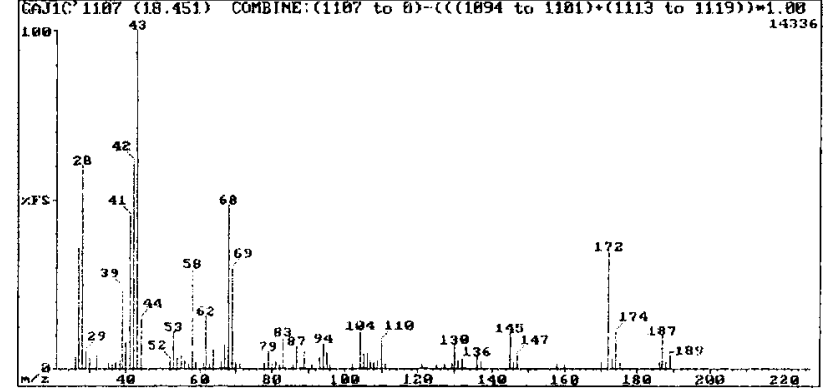

Figure 6. Mass spectrum of 6-chloro- $N^{4}$-propyl-1,3,5-triazine-2,4-diamine.<smiles>CCCNN=NNN(CC)CC</smiles>

1-sec-Butyl-4,4-diethyl-1-tetrazene (peak 1)<smiles>CCNc1nc(C)nc(NCC)n1</smiles>

$N^{2}, N^{4}$-Diethyl-6-methyl-1,3,5-triazine-2,4-diamine (peak 5)<smiles>CCCNc1nc(N)nc(Cl)n1</smiles>

6-Chloro- $N^{4}$-propyl-1,3,5-triazine-2,4-diamine (peak 7)

Figure 7. Molecular structures of the photolytical products.

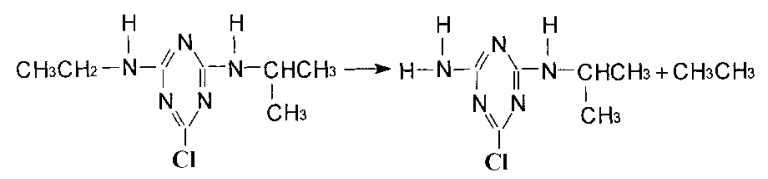<smiles>CCCNC1=NNC(NNc2nc(Cl)nc(N=NC(=NC)NN)n2)=NN1</smiles>

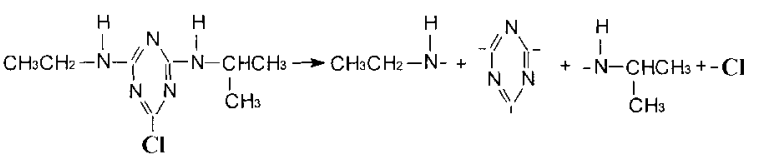<smiles>N=CC=CCN=NCCn1ncnn1</smiles><smiles>CNCC(C)C=NCCN=NCC(C)C</smiles><smiles>CCCCCCCCCCNNNCC</smiles>

$\mathrm{CH}_{3} \mathrm{CHCH}_{2}-\mathrm{N}=\mathrm{N}-+-\mathrm{N}-\mathrm{N}-\mathrm{CH}_{2} \mathrm{CH}_{3} \longrightarrow \mathrm{CH}_{3} \mathrm{CHCH}_{2}-\mathrm{N}=\mathrm{N}-\mathrm{N}-\mathrm{N}-\mathrm{CH}_{2} \mathrm{CH}_{3}$

$\mathrm{CH}_{3} \quad \mathrm{H} \mathrm{CH}_{2} \mathrm{CH}_{3} \quad \mathrm{CH}_{3} \quad \stackrel{\mathrm{H}}{\mathrm{CH}_{2} \mathrm{CH}_{3}}$

Figure 8. Formation of the three photolytical products. 
velocities of the first and fifth steps, and so speed up the photolysis of atrazine. The main components of the soil granules are the oxides and their hydrates of $\mathrm{Si}$, $\mathrm{Ti}, \mathrm{Fe}, \mathrm{Al}, \mathrm{Mn}$ and $\mathrm{Mg}$, which can adsorb atrazine molecules and rearrange or break the chemical bonds to form new compounds.

\subsection{Photolysis reactions}

Based on the results of GC-MS analysis of the photolysis products of atrazine, it is suggested that the following reactions occur. The chlorine substituent is lost, and the methyl subsitituent of the isopropyl group moves into its place, giving $N^{2}, N^{4}$-diethyl-6methyl-1,3,5-triazine-2,4-diamine. Alternatively, the $N^{2}$ ethyl is lost and the $N^{4}$ isopropyl group rearranges to $n$-propyl, giving 6 -chloro- $N^{4}$-propyl-1,3,5-triazine2,4 -diamine. In a more extended process, the alkyamino groups become detached, the triazine ring opens, as has been shown to occur under UV radiation, and the component parts rearrange to form 1-sec-butyl4,4-diethyl-1-tetrazene. These reactions as shown in Fig 8.

\section{CONCLUSION}

The photolysis of atrazine only occurs very close to the soil surface because of the low penetration of UV radiation. It was observed that, the coarser the soil, the less the UV penetration and the less the photolysis of atrazine. The rates of photolysis were greater in acid and basic soil than in neutral soil. Water, humic acid and surface-active agents could accelerate the photolysis of atrazine, and when the latter two were together photolysis was even more rapid. The photolytic process was approximately a first-order reaction (relative coefficient $>0.970$ ). The rate constant of photolysis ranged from 0.09 to $0.17 \mathrm{~min}^{-1}$, with a photolytic depth of $0.1-0.4 \mathrm{~mm}$ and a half-life of 4-8 $\mathrm{min}$.

Although the photolytic half-life of atrazine is $<8 \mathrm{~min}$, its decomposition in soil under field conditions is slow because of the weak intensity of UV radiation in solar light and the small photolytic depth
$(<0.3 \mathrm{~mm})$. The photolysis of atrazine involves five steps: movement, adsorption, distortion or breaking of chemical bonds, formation of new molecular species, and removal of photolytic products. Three main products have been identified: $N^{2}, N^{4}$-diethyl-6methyl-1,3,5-triazine-2,4-diamine, 6-chloro- $N^{4}$-propyl-1,3,5-triazine-2,4-diamine and 1-sec-butyl-4,4diethyl-1-tetrazene.

\section{ACKNOWLEDGEMENTS}

The work was supported by the National Natural Science Foundation of the People's Republic of China (29 777 026) and the Major Project Foundation of the Chinese Academy of Sciences (KZ951-B1-209-01)

\section{REFERENCES}

1 Solomon KR, Baker DB and Richards P, Ecological risk assessment of atrazine in North American surface waters. Envir Toxicol Chem 15:31-76 (1996).

2 Newman A, Atrazine found to cause chromosomal breaks. Envir Sci Tech 29:450A (1995).

3 Calvert JF and Pitts JN Jr, Photochemistry, Wiley, New York, USA (1996).

4 Pape BE and Zabik MJ, Photochemistry of selected 2-chloroand 2-methylthio-4,6-di(alkylamino)-s-triazine herbicides. $\mathcal{J}$ Agric Food Chem 18:202-207 (1970).

5 Pussemier L, Goux S and Vanderheyden V, Rapid dissipation of atrazine in soils taken from various maize fields. Water Res 37:171-179 (1997)

6 Maurino V, Minero C and Pelizzetti E, Phototransformation of atrazine over different metal oxide particles. NATO ASI Series, Ser 3 12:707-718 (1996).

7 Pulgarin CO, Schwitzguebel JP and Peringer PA, Abiotic oxidative degradation of atrazine on zero-valent iron activated by visible light. $\mathcal{F}$ Adv Oxide Technol 1:94-101 (1996).

8 Hustert K, Moza PN and Pouyet B, Photocatalytic degradation of atrazine by UV irradiation. Toxicol Envir Chem 31:97-102 (1991).

9 Pelizetti KV, Carlin V and Maurino V, Degradation of atrazine in soil through induced photocatalytic processes. Soil Sci 150:523-526 (1990).

10 Sposito G, Martin-Neto L and Yang A, Atrazine complexation by soil humic acids. F Envir Qual 25:1203-1209 (1996). 